\title{
Estandarización de la metodología para el conteo cromosómico en especies del género Polylepis en el Ecuador
}

\author{
Quija-Lamina, $\mathbf{P}^{1}$., Segovia-Salcedo, $C^{1,2}$, Jadán, M. ${ }^{1}$ \& Proaño K. ${ }^{1}$ \\ ${ }^{1}$ Departamento de Ciencias de la Vida, Carrera de Ing. en Biotecnología, ESPE, Sangolquí, Ecuador. \\ pauliquijiah@gmail.com \\ ${ }^{2}$ Universidad de Florida, Departamento de Biología, Florida Museum of Natural History \\ (FLMNH), Gainesville, USA
}

Recibido: 2010-05-21, aprobado: 2010-08-30

\begin{abstract}
RESUMEN.- El género Polylepis incluye 26 especies de árboles y arbustos que habitan desde Venezuela hasta la parte central de Argentina. Los bosques de Polylepis constituyen en su mayor parte la vegetación natural de los Andes con una fauna y flora sumamente especializada y de gran importancia ecológica. En las últimas décadas, varios intentos de clarificar su filogenia a través de técnicas moleculares no han tenido éxito. Debido posiblemente a la frecuente hibridización; otras hipótesis se centran en la poliploidía, la cual no ha sido analizada con éxito, debido a la falta de protocolos en el área de citogenética. Esta investigación presenta por primera vez una metodología estandarizada para la visualización y conteo de cromosomas, así como para la obtención de fases celulares en las especies del género Polylepis. Se utilizaron meristemos radiculares y botones florales para estandarizar la metodología. Adicionalmente, fueron llevados a cabo estudios del ciclo celular para determinar la hora apropiada de recolección de las muestras. Las placas preparadas permitieron obtener los números cromosómicos de las especies de Polylepis presentes en el Ecuador, los cuales revelan por primera vez la presencia de poliplodía dentro del género, proceso muy importante dentro de la diversificación de las especies.
\end{abstract}

PALABRAS CLAVE: Ciclo celular, conservación, cromosomas, índice mitótico, Polylepis

ABSTRACT.- The genus Polylepis include 26 species of trees and shrubs distributed from Venezuela to central Argentina. Polylepis forests are mostly natural vegetation of the Andes with a highly specialized fauna and flora and they have great ecological importance. In recent decades, several attempts to clarify their phyloge- 
ny through molecular techniques have not been successful. One of the possible reasons could be the frequent hybridization, other hypotheses focus on the presence of polyploidy, phenomenon that has not been tested with success, due to lack of protocols for conducting cytogenetic studies. This research has developed for the first time a standardized methodology for visualization and chromosome counting of genus Polylepis as well as data about the cellular phases. Root tips and flower buds were used to standardize the methodology. Additionally cell cycle studies were carried out to determine the proper time of collection of samples. The plates prepared allowed to obtain the chromosome numbers of Polylepis species present in Ecuador, which revealed for the first time, the presence of polyploidism in this genus, a very important condition in the diversification of the species.

KEYWORDS: Cell cycle, conservation, chromosomes, mitotic index, Polylepis

INTRODUCCIÓN.- El género Polylepis incluye 26 especies de árboles y arbustos que habitan desde los Andes Venezolanos hasta la parte central de Argentina (1). En el Ecuador encontramos ocho especies que pertenecen a los diferentes complejos evolutivos desde el grupo basal Sericea hasta el más derivado: el complejo Incana (2). Los bosques de Polylepis forman parte de la vegetación natural de los Andes con una fauna sumamente especializada. Sin embargo, la distribución actual de éstos ha sido disminuida de manera alarmante por procesos antropogénicos como agricultura, pastoreo, tala, quema e introducción de especies exóticas (2).

En las últimas décadas varios intentos de aclarar su filogenia a través de técnicas moleculares se han visto truncados por la falta de resolución en los análisis a nivel de especies (3). Una de las posibles razones de esta falta de claridad evolutiva se puede centrar en la frecuente hibridización entre las especies de este género, por razones naturales (polen que puede viajar largas distancias) y por reubicación de poblaciones debido a actividades humanas (reforestación no tecnificada; 4, 5, 6). Otras hipótesis se enfocan en la existencia de poliplodía en el género, la cual no ha podido ser analizada con éxito (7).

Los estudios cromosómicos son una herramienta importante y básica para el análisis intra e inter-poblacional, evolutivo y sistemático, permitiendo diferenciar especies morfológicamente similares o con un estatus taxonómico incierto. Los conteos cromosómicos mitóticos y meióticos son usados comúnmente para determinar hibridización, relaciones entre especies, análisis de cario- 
tipos y translocaciones (8), además constituyen la vía más directa para establecer niveles de ploidía $(9,10)$.

De igual manera, el análisis del ciclo celular presenta varias aplicaciones como eliminar el factor del azar y utilizar criterios objetivos para la toma de las muestras vegetales y esclarecer las causas que determinan el rol de la poliploidía $(11,12)$. Además, permite determinar la mejor hora del día para la prefijación, en función del número de células en división y de los componentes del índice mitótico (11). Estos datos constituyen las herramientas principales para aumentar la efectividad de los métodos químicos $\mathrm{y}$ físicos para la visualización de cromosomas en especies vegetales (13).

En el caso del género Polylepis, los estudios cromosómicos son relevantes para aclarar las hipótesis sobre poliploidía, así como supuestos de hibridización y apomixis (3). Sin embargo, dichos estudios no se han podido realizar debido a la falta de una metodología estandarizada que permita la visualización de cromosomas metafásicos.

Simpson (16) menciona, en su estudio sistemático, que los ensayos no dieron resultados específicos, y Kessler (15) observó números cromosómicos de 80 en muestras de raíces meristemáticas en tres especies de Polylepis, pero el conteo exacto no fue posible debido al tamaño reducido de los cromosomas que fácilmente se pueden confundir con partículas del colorante y suciedades (3). Posteriormente, Schmidt-Lebuhn et al., aseguran que debido al tamaño de los cromosomas y a la dificultad de determinar metafases en este género, es virtualmente imposible obtener conteos cromosómicos (14).

La presente investigación presenta una metodología estandarizada que permite la visualización de fases celulares y cromosomas metafásicos en las especies del género Polylepis, presentes en el Ecuador. Método que nos permitirá obtener por primera vez los números cromosómicos para el género Polylepis, datos sumamente importantes y básicos para aclarar las hipótesis sobre su origen y evolución.

Además, los estudios del ciclo celular en $P$. pauta y $P$. incana permitirán realizar análisis genéticos comparativos para la determinación de mecanismos citológicos como la duplicación somática y la no reducción de los gametos que inducen poliploidía en plantas (17).

\section{MATERIALES Y MÉTODOS}

Muestras de meristemo radicular y botón floral de las especies del género Polylepis fueron obtenidas para estandarizar la metodología para la obtención de cromosomas metafásicos, así como células en diferentes fases del ciclo celular. Diferentes variaciones en los procesos de pretratamiento, fijación, hidrólisis, tinción y preparación de placas, en base a las características 
de los cromosomas observados en ensayos previos fueron utilizadas para la estandarización de la metodología.

\section{Recolección de las muestras vegetales}

Se utilizaron muestras de meristemos radiculares (1-2 $\mathrm{cm}$ de longitud) y ovarios de botones florales de las especies de género Polylepis las cuales fueron colectadas durante los meses de junio y julio del 2008, en diferentes localidades de los páramos ecuatorianos.

Se tomaron datos de localización geográfica, localidad, especie y tipo de muestras de cada una de las poblaciones. Se colectaron plántulas de $5-10 \mathrm{~cm}$ y muestras de botones florales (Tabla 1). Las plántulas fueron transportadas con técnica del Ejército, en donde fueron transferidas a macetas con un sustrato apropiado para su enraizamiento con la finalidad de obtener muestras de meristemo radicular en forma regular y en cantidades adecuadas para la estandarización de la metodología.

Los botones florales encontrados fueron pretratados en el sitio de colección y transportados en un contenedor que permitía mantenerlos a temperaturas bajas. En el laboratorio, después del proceso de fijación y lavado, las muestras se almacenaron a $-20{ }^{\circ} \mathrm{C}$ en etanol al $70 \%$ hasta su posterior uso.

\section{Estudio del ciclo celular}

Los estudios del ciclo celular fueron realizados en muestras de meristemo radicular en dos especies del género

Tabla 1. Muestras de las especies del género Polylepis con sus detalles de localidad, puntos de localización geográfica (GPS) y tipo de muestra colectada.

\begin{tabular}{|c|c|c|c|}
\hline Especie & Localidad & Puntos GPS & Muestra \\
\hline \multirow[t]{4}{*}{ P. incana } & Illinizas & $\mathrm{S} 00^{\circ} 12^{\prime} 8.56^{\prime \prime} \mathrm{W} 68^{\circ}{ }^{\circ} 40^{\prime} 24.65^{\prime \prime}$ & $\begin{array}{l}\text { Plántulas, } \\
\text { Botón floral }\end{array}$ \\
\hline & Papallacta & S 00 019' 01.0" W $78^{\circ}$ o13' 28.6" & $\begin{array}{l}\text { Plántulas, } \\
\text { Botón floral }\end{array}$ \\
\hline & El Ángel, Potrerillos & N $00^{\circ} 48^{\prime} 31.6^{\prime \prime}$ W 77 058' 31.9" & Plántulas \\
\hline & Mojanda & N $00^{\circ} 08^{\prime} 18.9 "$ W 78 05' 17.4" & $\begin{array}{l}\text { Plántulas, } \\
\text { Botón floral }\end{array}$ \\
\hline \multirow[t]{2}{*}{ P. pauta } & Papallacta & S 00 020' 41.5" W $78^{\circ} 12^{\prime} 2.0^{\prime \prime}$ & $\begin{array}{l}\text { Plántulas, } \\
\text { Botón floral }\end{array}$ \\
\hline & Mojanda & N $000^{\circ} 08^{\prime} 07.4^{\prime \prime} \mathrm{W} 78^{\circ} 15^{\prime} 22.5^{\prime \prime}$ & $\begin{array}{l}\text { Plántulas, } \\
\text { Botón floral }\end{array}$ \\
\hline
\end{tabular}

bloques de tierra hasta los invernaderos del laboratorio de la Carrera de Ingeniería en Biotecnología de la Escuela Poli-
Polylepis: P. pauta de la localidad de Papallacta, Páramo de Guamaní y $P$. incana de los Illinizas. El cálculo del 
tamaño la muestra "n" o número de células en mitosis a analizar por cada hora de colección, fue determinado mediante la fórmula del tamaño muestral para la estimación de la proporción poblacional (18).

$$
n=\frac{\mathrm{Z}_{\mathrm{a} / 2}^{2} \mathrm{~S}^{2}}{\mathrm{E}^{2}}
$$

Donde la expresión $Z_{2}^{2}$ a/2 corresponde al percentil de la ley normal estándar cuyo valor es de 1.96 para un $95 \%$ de confianza en el estudio, $S^{2}$ es la varianza de la proporción, su valor es de 0,25 , ya que la varianza se maximiza con una proporción poblacional estimada de 0,5 , debido a la ausencia de estudios previos en el género y $\mathrm{E}^{2}$ es el error máximo permitido del $5 \%$.

Para calcular el tamaño muestral total a analizar que incluye células en interfase, se realizó una prueba piloto en $P$. incana con un total de 3.751 células de las cuales 1.332 eran mitóticas, esto nos indica que por cada 2,82 células una se encuentra en mitosis. En consecuencia, se debe multiplicar 2,82 por el tamaño muestral mitótico (385), determinado mediante la ecuación para obtener el número de células totales que se deben contabilizar por cada hora de colección para obtener resultados con el $95 \%$ de confianza, el resultado es de 1.085 células. Los datos tomados de la prueba piloto demuestran que se puede encontrar en promedio 6,76 células en mitosis por cada imagen proyectada, por lo que para lograr obtener las 385 células mitóticas y por ende las 1.085 células totales, 60 imágenes diferentes fueron analizadas.

Preparación de las placas. Para el estudio del ciclo celular se colectaron de tres a cuatro raíces meristemáticas de 1 a $2 \mathrm{~cm}$ de longitud directamente en el fijador Carnoy (etanol:ácido acético $1: 3$; 19), cada 30 minutos, desde las 7:30h hasta las 18:00 h. Después de hidrolizar con $\mathrm{HCl}$ (ácido clorhídrico) $1 \mathrm{~N}$ durante 25 minutos a $60{ }^{\circ} \mathrm{C}$ y teñir con aceto-carmín al 1\% durante al menos tres horas a temperatura ambiente, se prepararon las placas para su observación.

Recopilación de datos. Fueron preparadas al menos tres placas, para examinar un total de 60 imágenes (20 por cada placa). Se anotaron las frecuencias de interfases, profases, metafases, anafases y telofases encontradas en cada imagen y se capturaron aquellas donde se observaron las mejores células en cada fase. Las microfotografías fueron tomadas con una cámara fotográfica digital de 20 MPX adaptada al microscopio invertido marca LOMO con un aumento de $1.040 \mathrm{X}$.

Análisis de los datos. Los cálculos del índice mitótico (IM) y los índices de fases (IF), parciales y totales se llevaron 
a cabo mediante las ecuaciones utilizadas por Matos \& Molina (1997) (22) en trabajos realizados con Aloe vera.

$$
\begin{gathered}
I M=\frac{\text { No. células en mitosis }}{\text { No. células totales }} \times 100 \\
I F=\frac{\text { No. células en fase }}{\text { No. total de células en mitosis }} \times 100
\end{gathered}
$$

\section{Pretratamiento}

Meristemo radicular. Una vez conocida la o las horas apropiadas para la recolección de las muestras, se colectaron meristemos radiculares limpios de $1-2 \mathrm{~cm}$ de longitud en microtubos que contenían los diferentes agentes antimitóticos, permitiéndonos variar tanto la concentración, como la temperatura y el tiempo de aplicación para la estandarización del proceso (Tabla 2).
También fueron probadas temperaturas bajas durante 4 horas antes de usar los agentes químicos.

Botones florales. Las muestras fueron pretratadas a diferentes horas del día en los sitios de colección en 8 hidroxiquinolina $2 \mathrm{mM}$ y agua helada durante 24 horas a $4{ }^{\circ} \mathrm{C}(20,19)$, razón por la cual no se determinó la hora de colección.

\section{Fijación}

Meristemo radicular. Se usaron diferentes soluciones de fijación: ácido acético, etanol $(1: 3 ; 26)$ ácido acético, cloroformo, etanol $(1: 3: 6 ; 19)$ y metanol, ácido propiónico, cloroformo $(6: 3: 2 ; 21)$. Los meristemos radiculares después de varios lavados con agua

Tabla 2. Agentes inhibidores de la mitosis, con sus detalles de variación en la concentración, tiempo y tem-

\begin{tabular}{|c|c|c|c|}
\hline \multirow[t]{2}{*}{ Agente } & \multicolumn{3}{|c|}{ Tratamiento } \\
\hline & centración & Periodo & Temperatura \\
\hline Agua helada & & $\begin{array}{c}24 \text { horas } \\
48 \text { horas } \\
4 \text { horas }\end{array}$ & $\begin{array}{l}4{ }^{\circ} \mathrm{C} \\
0{ }^{\circ} \mathrm{C}\end{array}$ \\
\hline \multirow[t]{3}{*}{ 8-hidroxiquinolina } & $2 \mathrm{mM}$ & 3 horas & $4{ }^{\circ} \mathrm{C}$ \\
\hline & & $\begin{array}{l}4 \text { horas } \\
5 \text { horas } \\
24 \text { horas }\end{array}$ & $\mathrm{RT}^{*}$ \\
\hline & & \multicolumn{2}{|c|}{ I hora RT más $24 \mathrm{~h} \mathrm{a} 4{ }^{\circ} \mathrm{C}$} \\
\hline Colchicina & $\begin{array}{l}0,2 \% \\
0,5 \%\end{array}$ & $\begin{array}{l}1 \text { hora } \\
2 \text { horas } \\
3 \text { horas }\end{array}$ & RT \\
\hline
\end{tabular}
peratura utilizados para estandarizar el proceso de pretratamiento en muestras de meristemo radicular.

${ }^{*} \mathrm{RT}$, Temperatura ambiente $\left(16-18^{\circ} \mathrm{C}\right)$. 
destilada fueron fijadas en dichas soluciones ensayándose diferentes tiempos: $4,21,22,23,24$ y 48 horas, a diferentes temperaturas: $4{ }^{\circ} \mathrm{C}$ y a temperatura ambiente. En caso de no usarlas inmediatamente, luego de la fijación se repiten los lavados y se preservan en alcohol al $70 \%$ a $-20{ }^{\circ} \mathrm{C}$, hasta su posterior uso.

Botones florales. Las muestras pretratadas en el lugar de colección, fueron fijadas en una solución de etanol, ácido acético $(3: 1 ; 19)$ durante 24,48 y 72 horas a $4{ }^{\circ} \mathrm{C}$. Posteriormente fueron lavadas para ser preservadas en etanol al $70 \%$ a $-20{ }^{\circ} \mathrm{C}$, hasta su posterior uso.

\section{Hidrólisis}

Meristemo radicular. Después de lavar la muestra se utilizó una hidrólisis con $\mathrm{HCl} 1 \mathrm{~N}$ a $60{ }^{\circ} \mathrm{C}(11)$, ensayando diferentes tiempos $(5,10,15,20,25$, 30,40 y 60 minutos).

Botones florales. Fueron retirados del etanol al 70\% y disectados para obtener los ovarios y estambres (Figura 1), los cuales fueron lavados para someterlos al proceso de hidrólisis en $\mathrm{HCl} 1 \mathrm{~N}$ a 60 ${ }^{\circ} \mathrm{C}(11)$, ensayando diferentes tiempos (5, $10,15,20$ y 25 minutos).

Tinción y preparación de placas. Fueron probados diferentes colorantes: aceto-carmín/orceína $1 \%$, aceto-carmín/orceína $2 \%$, propiónico car-

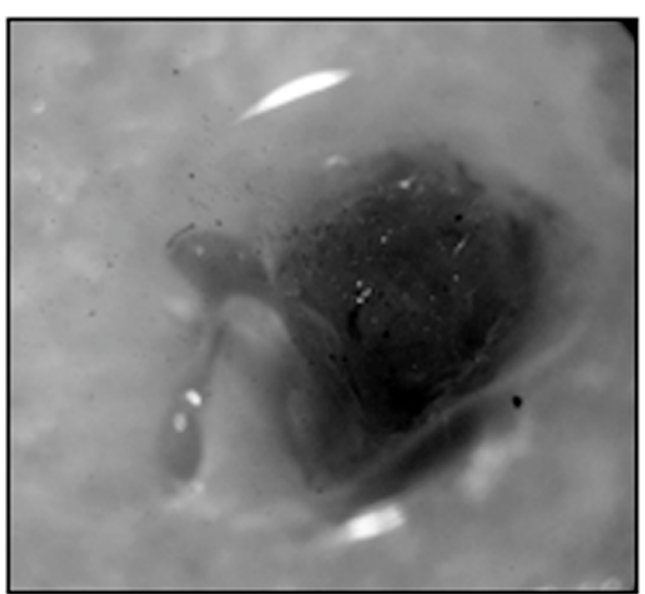

Figura 1. Botón floral de $P$. incana disectado para obtener el ovario y los estambres (2.5X).

mín/orceína 1\%, lacto-propiónico orceína 2\% $(26,27)$ y Reargent Shiff (10). Después de hidrolizar y lavar la muestra, se colocó el colorante en el microtubo, durante diferentes periodos de tiempo: 1, 2, 3 y 24 horas, a temperatura ambiente y $60{ }^{\circ} \mathrm{C}$. Una vez teñidas las muestras, se prepararon las placas con la técnica convencional del aplastado o squash (11).

\section{RESULTADOS Y DISCUSIÓN}

Estudio del ciclo celular. El estudio microscópico de las células mitóticas e interfásicas en meristemos radicales permitió conocer cuantitativamente el proceso de división mitótica en las dos especies del género Polylepis: $P$. incana y $P$. pauta cuyos resultados y análisis son presentados por primera vez para estas especies. 


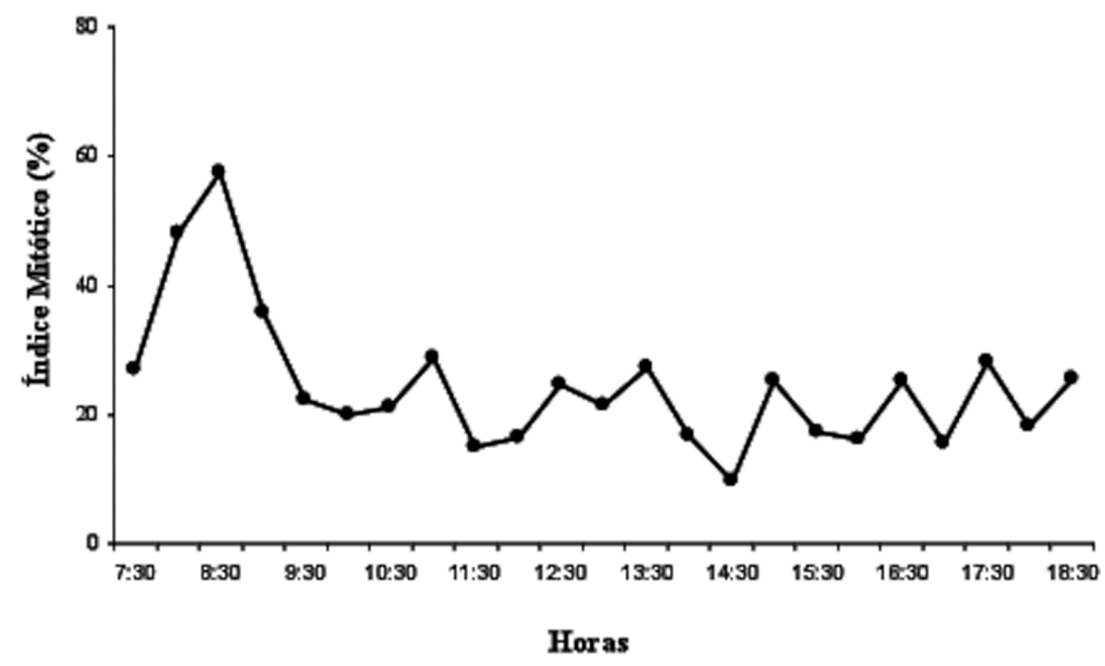

Figura 2. Secuencia del ciclo celular en $P$. incana de los Illinizas en un periodo de recolección de12 horas

La determinación del ciclo celular y de la hora mitótica constituyen las herramientas principales para aumentar la efectividad de los métodos químicos $\mathrm{y}$ físicos usados en la preparación y visualización de los cromosomas en especies vegetales, así como la eliminación del azar, utilizando criterios objetivos para la toma de las muestras. De igual manera permiten determinar la presencia de poliploidía como un proceso de diversificación de las especies propias de zonas montañosas $(13,11)$. La información obtenida en esta investigación en relación al ciclo celular ofrece la oportunidad de investigar procesos de poliplodía en este género, no solamente en las especies ecuatorianas si no a nivel regional.

Para la estimación del ciclo mitótico en las dos especies del género Polylepis, P. incana y P. pauta, fueron analizadas un total de 55200 células, discriminadas en células en interfase y células en mitosis. En base a la evaluación de un período de 12 horas de los índices de fase (IF) e índice mitótico (IM) parciales y totales, se estableció que la mejor hora para la prefijación de las muestras de meristemo radicular en $P$. incana, está comprendida entre las 08:00h y 08:30h (IM=57,50 \%). Durante las demás horas los IM fueron bajos, fluctuando entre el $9 \%(14 \mathrm{H} 30)$ y $28 \%(11 \mathrm{H} 00)$ de la población celular (Figura 2). Es posible observar que el porcentaje de profases ocupa la mayor parte de la población celular en división, especialmente entre las 08:00h y 08:30h. Durante las otras horas, las fases restantes (metafases, anafases y telofases) se presentan en pequeña proporción, en forma irregular (Figura 3). 


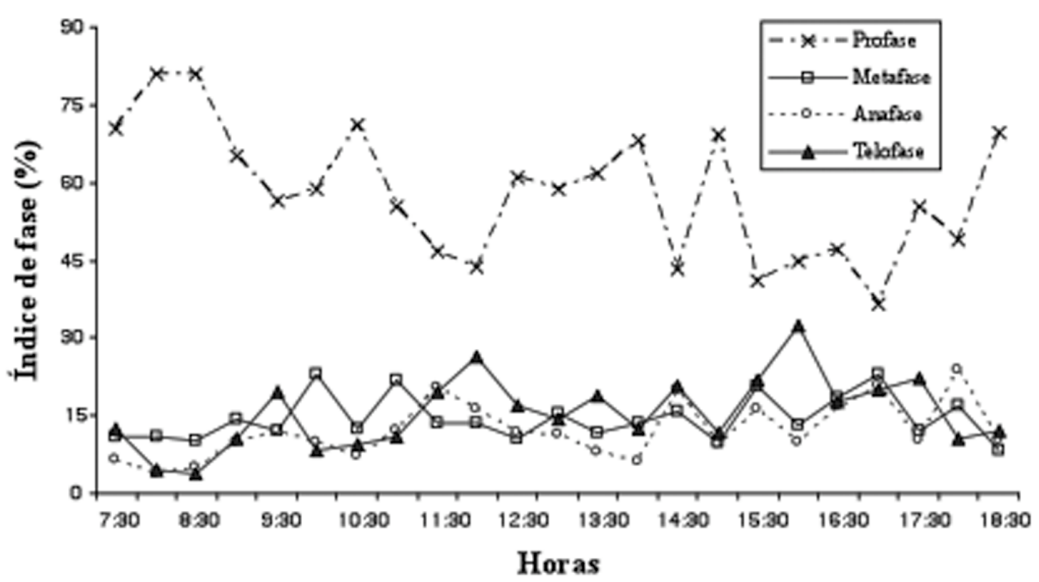

Figura 3. Secuencia de los índices de fase en P. incana de los Illinizas en un periodo de recolección de 12 horas.

La mejor hora para la prefijación de las muestras de meristemo radicular en $P$. pauta, está comprendida entre las 8:00h y 9:30h (IM $=43,08-49,00 \%)$, observando un pico mayor a las $8: 30 \mathrm{~h}$ (IM = $53,92 \%)$. Durante las demás horas los IM fueron bajos, fluctuando entre el $14 \%$ $(17: 00$ h) y $37 \%$ (10:00 h) (Figura 4).
De igual manera, es posible observar que el porcentaje de profases ocupa la mayor parte de la población celular en división, especialmente entre las 08:00h y 10:00h. Durante las demás horas, se nota una acumulación leve de telofases. Las fases restantes (metafases y anafases) se presentan en pequeña proporción, en forma irregular (Figura 5).

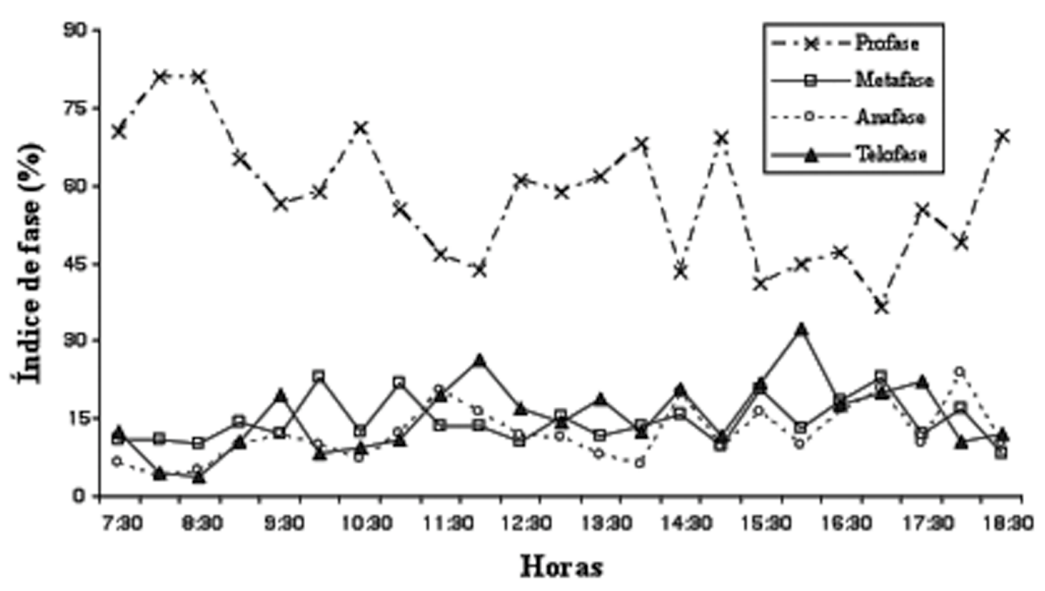

Figura 4. Secuencia del ciclo celular en P. pauta del Páramo de Guamaní - Papallacta, en un periodo de recolección de 12 horas. 


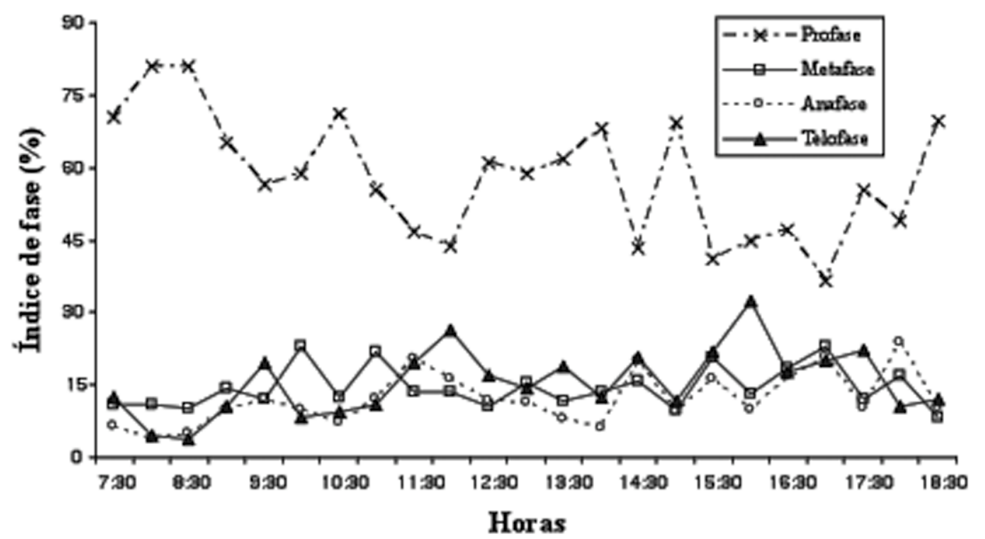

Figura 5 Secuencia de los índices de fase en P. pauta del Páramo de Guamaní-Papallacta, en un periodo de recolección de12 horas.

Las horas de colección obtenidas para las dos especies son consistentes con otras investigaciones donde el mayor número de células en mitosis se observan en las primeras horas de la mañana hasta aproximadamente las 11:00h. Sin embargo, es importante tomar en cuenta que el momento del día en el cual las células se multiplican con mayor rapidez varía de una especie a otra (22).

La curva de la Figura 2 nos permite asumir un valor medio de 2 horas para un ciclo de división celular completo en $P$. incana, por lo que la duración del ciclo mitótico en base a la evaluación de los índices de fase (IF) e índices mitóticos (IM) totales es de 29 minutos, de los cuales 18 minutos son ocupados por la profase; cuatro minutos por la metafase, tres minutos por la anafase y cuatro minutos por la telofase. En $P$. pauta la Figura 4 nos permite asumir un valor medio de tres horas para un ciclo de división celular completo, por lo que la duración del ciclo mitótico en base a la evaluación de los IF e IM totales, es de 53 minutos, de los cuales 35 minutos son ocupados por la profase; seis minutos por la metafase, cuatro minutos por la anafase y siete minutos por la telofase. En las Figuras 6 y 7 se muestran fotografías de fases mitóticas observadas en las especies evaluadas.

Se destaca un mayor tiempo para las células en interfase, aunque una vez iniciada la actividad mitótica, las células permanecen más tiempo en profase, la anafase dura un lapso más corto, lo que concuerda con Raven, Evert \& Curtis (1976) (23) quienes señalan que las fases de la mitosis son variables en longitud siendo la profase la más larga y la anafase la más corta. En este sentido, las frecuencias de las fases mitóticas permanecen dentro de los rangos normales reportados $(23,24)$. 


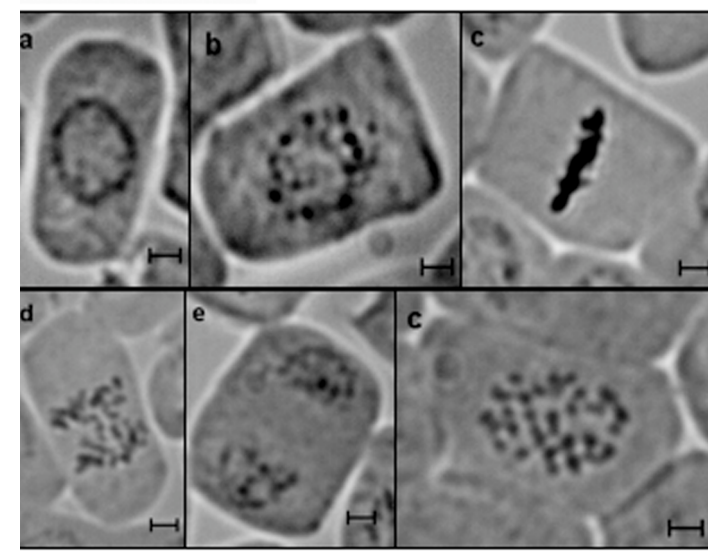

Figura 6. Algunas de las fases mitóticas observadas en P. incana de los Illinizas. (a) Interfase, (b) Profase, (c) Metafase, (d) Anafase, (e) Telofase. Barra representa $5 \mu \mathrm{m}$.

La variación presentada tanto en la hora de colección como en la duración del ciclo mitótico y sus distintas fases en $P$. incana y $P$. pauta, se debe posiblemente a la propiedades celulares de cada especie y a su distinta reacción ante la acción de factores ambientales (11), probablemente se obtendrán resultados diferentes en las mismas especies bajo diferentes condiciones.

En las dos especies se registra cierta irregularidad en el curso del ciclo celular, caracterizado por un mayor porcentaje de profases dentro de la población celular en división y a una acumulación de telofases en $P$. pauta, indicándonos la presencia ciclos irregulares. La alternancia de interfases normales con mitosis irregulares en otras especies analizadas como oca y olluco, constituyen uno de los probables mecanismos de poliploidización (11).

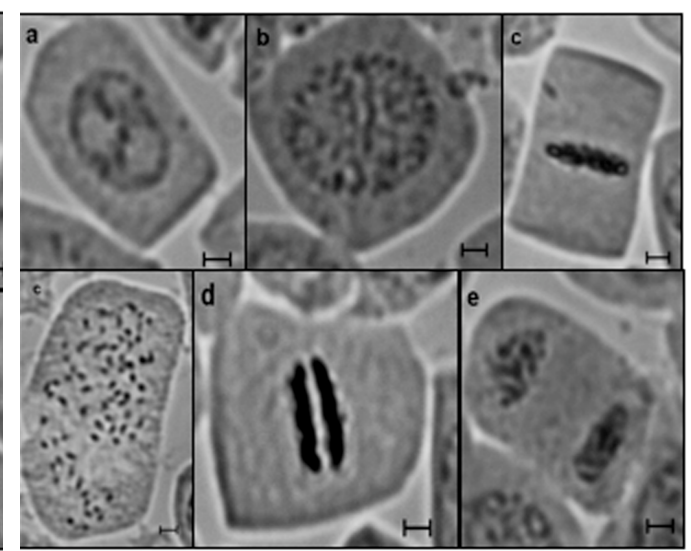

Figura 7. Algunas de las fases mitóticas observadas en P. pauta del Páramo de Guamaní. (a) Interfase, (b) Profase, (c) Metafase, (d) Anafase y (e) Telofase. Barra representa $5 \mu \mathrm{m}$

Estandarización de la metodología. La metodología que se logró estandarizar para el conteo cromosómico utilizando muestras de meristemo radicular y botón floral, para las especies del género Polylepis, no se basó en un protocolo específico, sino sobre la base de las características de los cromosomas descritos por Kessler (1995) (28) en tres especies de Polylepis: $P$. neglecta, P. triacontandra, P. tarapacana, quien observó numerosos cromosomas $(2 \mathrm{n}=$ 82) de tamaños sumamente pequeños, los que se confundían con las partículas de colorante (3).

\section{Pretratamiento de las muestras.}

Otro factor crítico, a más de la determinación de la hora de colección apropiada, para mejorar los resultados del proceso de pretratamiento, es el tipo de agente inhibidor de la mitosis que se utiliza (25). 
En los pretratamientos con agentes químicos no se obtuvo buena condensación y dispersión de los cromosomas como se observó al utilizar temperaturas bajas positivas de $4{ }^{\circ} \mathrm{C}$ (Figura 8). La utilización de frío o calor, previo al tratamiento con sustancias químicas, ayuda a desestabilizar los microtúbulos. Además, el tratamiento previo de meristemos radiculares con frío induce la acumulación de células en metafase (26) condición deseable para la realización de pretratamientos con agentes químicos. Sin embargo, en este caso la utilización de frío no ayudó a mejorar la acción de la 8-hidroxiquinolina. Por lo que se sugiere utilizar como pretratamiento, agua destilada a 4 ${ }^{\circ} \mathrm{C}$ durante 24 horas, la cual se recomienda cuando las especies a estudiar poseen numerosos cromosomas (19), como es el caso del género Polylepis.

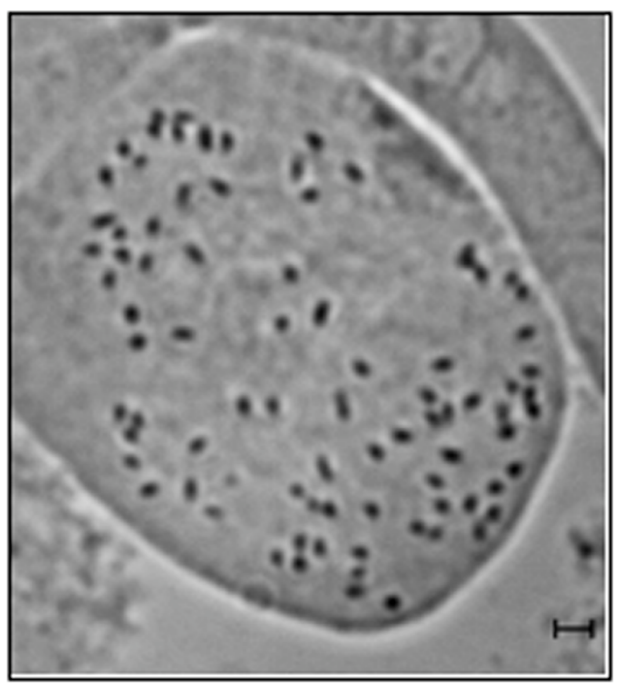

Figura 8. Cromosomas metafásicos en muestras de meristemo radicular de P. microphylla de la localidad de Achupallas. Barra representa $5 \mu \mathrm{m}$.
Se deben usar períodos de al menos 24 horas y no más de 26 horas en agua destilada a $4{ }^{\circ} \mathrm{C}$, ya que la longitud de los cromosomas se acorta considerablemente (19) y las células se destruyen. Los periodos cortos (cuatro horas) tampoco arrojan buenos resultados, no se observa destrucción celular pero tampoco cromosomas claros e individuales. Con la utilización de la temperatura de congelación, se destruyen las células y sus componentes. Para las muestra de botones florales funcionan bien los pretratamientos utilizados en meristemo radicular.

Fijación de las muestras. Las tres mezclas de fijación, ensayadas durante 24 horas a $4{ }^{\circ} \mathrm{C}$ proporcionaron buenos resultados en la interrupción de los procesos vitales de la célula sin dañar su estructura (4). Se prefirió usar Carnoy (ácido acético:etanol 1:3; 19) ya que las otras mezclas contenían cloroformo, el cual es un químico nocivo para la salud y el medio ambiente.

Hidrólisis de las muestras. El proceso de hidrólisis con $\mathrm{HCl} 1 \mathrm{~N}$ a $60{ }^{\circ} \mathrm{C}$ fue estandarizado para las muestras de meristemo radicular, ovario y estambre, obteniéndose diferentes períodos de tiempo, los cuales dependen de la naturaleza del tejido (20). En las muestras de ovario y estambre se obtuvo una buena separación de las células sin destrucción de las mismas con cinco y diez 
minutos respectivamente, tiempo menor al utilizado con raíces meristemos radiculares (25-30 minutos), debido probablemente a que tanto el tejido del ovario como el del estambre son blandos y están protegidos por las otras estructuras florales externas a diferencia de la raíz que está expuesta directamente al suelo.

Tinción de las muestras. La superposición, la pobre coloración y el tamaño extremadamente pequeño de los cromosomas son factores que han limitado los estudios citogenéticos (27). Sin embargo, el uso de aceto-carmín o aceto-orceína ha facilitado la obtención de buenos resultados (28) en las especies donde se han observado dichos factores como es el caso de las del género Polylepis (3). En el presente estudio, de todos los colorantes probados, sólo el uso del aceto-carmín al $1 \%$ permitió obtener una tinción adecuada de los cromosomas, fases celulares y citoplasmas claros en las muestras de meristemo radicular y ovario.

La partículas del colorante que pueden confundirse con los cromosomas han impedido también obtener conteos exactos en ensayos anteriores en algunas especies de Polylepis $(15,16)$, ésta dificultad fue superada usando el colorante en baja concentración (1\%) y filtrándolo, cada vez antes de utilizarlo, aunque esto impli- caba un mayor tiempo de tinción, el cual se reduce calentando las muestras en el colorante. Cabe recalcar que concentraciones mayores del colorante destruyen el tejido. Una vez teñidas las muestras pueden permanecer en el colorante, debido a que el ácido acético del mismo actúa también como fijador (20), pero se deben evitar dejarlas durante largos periodos de tiempo ya que las partículas del colorante tienden a sedimentar acumulándose en el tejido. Se recomienda mantener las muestras en refrigeración para evitar la proliferación de bacterias.

Números Cromosómicos. Los cromosomas son reconocidos por su importancia en los estudios taxonómicos y evolutivos. El número cromosómico, teniendo en cuenta dos variables: el número básico y el nivel de ploidía, constituyen datos relevantes para la resolución de problemas taxonómicos y la comprensión de las tendencias evolutivas $(29,11)$. A pesar de esta importancia, los estudios cromosómicos completos en las especies del género Polylepis no han sido realizados, se han intentado conteos cromosómicos desde 1979 sin resultados específicos (3).

En el presente trabajo, se presentan por primera vez los números cromosómicos (2n) de la especies del Género Polylepis presentes en el Ecuador (Tabla 3), iniciando de esta manera el 
Tabla 3. Números cromosómicos somáticos de las especies del género Polylepis con detalles de muestra utilizada, localidad y número de células metafísicas analizadas.

\begin{tabular}{|c|c|c|c|c|c|}
\hline Especie & Muestra & Localidad & $\begin{array}{c}\text { No } \\
\text { células }\end{array}$ & No. Cromosomas & $2 n$ \\
\hline \multirow[t]{4}{*}{ P. incana } & Meristemo & El Ángel & 2 & $38(1), 40(1)$ & $38-40$ \\
\hline & radicular & Illinizas & 23 & $38(11), 39(5), 40(4), 41(1), 42(2)$ & $38-42$ \\
\hline & & Papallacta & 25 & $39(2), 40(7), 41(9), 42(7)$ & $39-42$ \\
\hline & Ovario & Papallacta & 15 & $40(7), 41(3), 42(5)$ & $40-42$ \\
\hline \multirow[t]{4}{*}{ P. pauta } & Meristemo & Papallacta & 1 & $71(1)$ & 71 \\
\hline & $\begin{array}{l}\text { Radicular } \\
\text { Oyario }\end{array}$ & Papallacta & 25 & $67(9), 68(2), 72(2) 73(2)$ & $67-83$ \\
\hline & & & & $\begin{array}{l}74(1) 75(1), 76(3), 77(1), \\
78(1), 80(1), 81(1), 83(1)\end{array}$ & \\
\hline & & Mojanda & 12 & $\begin{array}{l}70(6), 71(1), 72(1), 73(1), \\
75(1), 78(1), 84(1)\end{array}$ & $70-84$ \\
\hline \multirow[t]{3}{*}{ P. sericea } & Ovario & El Ángel & 8 & $37(5), 39(2), 40(1)$ & $37-40$ \\
\hline & & Fierrourco & 25 & $39(10), 40(6), 41(7), 42(2)$ & $39-42$ \\
\hline & & Yanacocha & 9 & $\begin{array}{l}59(2), 64(1), 66(1), 10(1), \\
71(1), 74(1), 76(1), 77(1)\end{array}$ & $59-77$ \\
\hline P. microphylla & $\begin{array}{l}\text { Meristemo } \\
\text { radicular }\end{array}$ & Achupallas & 25 & $\begin{array}{l}70(3), 71(1), 72(1), 73(2), \\
74(4), 75(2), 76(1), 77(5), \\
78(2), 79(2), 82(2)\end{array}$ & $70-82$ \\
\hline \multirow[t]{3}{*}{ P. weberbauri } & Meristemo & Zhud & 10 & $37(9), 42(1)$ & $37-42$ \\
\hline & Radicular & & & & \\
\hline & Ovario & Zhud & 16 & $\begin{array}{l}37(7), 38(1), 39(4), 40(2), \\
41(1), 42(1)\end{array}$ & $37-42$ \\
\hline P. lanuginosa & $\begin{array}{l}\text { Meristemo } \\
\text { radicular }\end{array}$ & Zhud & $\begin{array}{c}25 \\
42(5)\end{array}$ & $38(2), 39(8), 40(5), 41(5)$ & $38-42$ \\
\hline \multirow[t]{2}{*}{ P. reticulata } & Meristemo & Oyacachi & 15 & 87(2), 94(1), 96(1), 104(3), & $87-118$ \\
\hline & Ovario & Soldados & 11 & $\begin{array}{l}36(5), 38(1), 39(1), 40(2), \\
41(1), 42(1)\end{array}$ & $36-42$ \\
\hline \multirow[t]{2}{*}{ P. racemosa } & $\begin{array}{l}\text { Meristemo } \\
\text { Radicular }\end{array}$ & Oyacachi & 25 & $\begin{array}{l}\text { 69(9), 70(4), 71(3), 72(2), } \\
74(3), 76(2), 78(1), 80(1)\end{array}$ & $69-80$ \\
\hline & Ovario & Oyacachi & 2 & $72(1), 77(1)$ & $72-77$ \\
\hline
\end{tabular}


conocimiento cromosómico de este género y contribuyendo a su delimitación taxonómica. La variación presentada en los números cromosómicos dentro de las especies y entre poblaciones de la misma especie nos confirma, por primera vez, la presencia de poliploidía en el género en poblaciones naturales, lo cual estaría indicando la importancia de los cambios cromosómicos numéricos en la diversificación de las especies de este género, posiblemente debido a causas, entre ellas medioambientales, que aún no están muy claras.

Teniendo esta diversidad de números cromosómicos y niveles de ploidía, es obvio que tanto la aneuploidía como la poliploidía han jugado un rol importante en la evolución del género Polylepis, así como en otros, lo cual lo convierte también en un género atractivo para el análisis de dichos eventos (25). En el futuro, sería interesante estudiar los cromosomas de un mayor número de poblaciones, establecer las relaciones entre los niveles de ploidía y su localización geográfica, hábitat, etc. Además, sugerir modelos evolutivos para las especies de este género cuyo rol ecológico es fundamental para el ecosistema en donde habita. En la Figura 8 se presenta una fotografía de cromosomas metafísicos de P. microphylla, resultado de la utilización de la metodología antes descrita.

\section{AGRADECIMIENTOS}

Este estudio se realizó gracias al apoyo económico del Proyecto Páramo Andino, Tropical Development and Conservation Program y la Escuela Politécnica del Ejército con su programa de iniciación científica ESPE 2008.

\section{BIBLIOGRAFIA}

1. KESSLER, M., \& SCHMIDTLEBUHN, A. 2006. Taxonomical and distributional notes on Polylepis (Rosaceae). Diversity and Evolution, 6, 67-69.

1. JAMESON, S., \& RAMSAY, P. 2007. Changes in high-altitude Polylepis forest cover and quality in the Vilcanota Cordillera, Peru 19562005. Biological Conservation, 138, 38-46.

2. SCHMIDT-LEBUHN, A, KESSLER, M., \& KUMAR, M. 2006. Promiscuity in the Andes: Species Relationships in Polylepis (Rosaceae, Sanguisorbeae) Based on AFLP and Morphology. Systematic Botany, 31, 547-559.

3. SELTMANN, D., COCUCCI, A., HENSEN, I., \& JUNG, J. 2007. Fragment size, pollination efficiency and reproductive success in natural populations of wind-pollinated Polylepis australis (Rosaceae) trees. Flora, 202, 547-554. 
4. HOCH, G., \& KÖRNER, C. 2005. Growth, demography and carbon relations of Polylepis trees at the world's highest tree line. Functional Ecology, 19, 941-951.

5. CIERJACKS, A., IGLESIAS, K., WESCHE, K., \& HENSEN, I. 2007. Impact of sowing, canopy cover and litter on seedling dynamics of two Polylepis species at upper tree lines in central Ecuador. Journal of Tropical Ecology, 23, 309318.

6. SCHMIDT-LEBUHN, A., SELTMANN, P., \& KESSLER, M. 2007. Consequences of the pollination system on genetic structure and pattern of species distribution in the Andean genus Polylepis (Rosaceae): a comparative study. Plant Systematic and Evolution, 266, 91-103.

7. ORTIZ, V. 2007. Chromosome numbers, nuclear DNA content, and polyploidy in Consolea (Cactaceae), an endemic cactus of the Caribbean Islands. American Journal of Botany, 94, 1360-1370.

8. PÉREZ, R., HERNÁNDEZ, M., ROSE, V., CALLEROS, V., \& PANZERA, F. 2003. Citotaxonomía y evolución cromosómica en Triatominae, insectos vectores de la enfermedad de Chagas (heteropterareduviidae). Entomology Vector 10: 543-550.
9. TUNA, M., VOGEL, P., ARUMUGANATHAN, K. \& GILL, S. 2001. DNA content and ploidy determination of bromegrass germplasm accessions by flow cytometry. Crop Science, 41, 1629-1634.

10. SEMINARIO, J. 2004. Raíces andinas: Contribuciones al conocimiento y a la capacitación. Serie: Conservación y uso de la biodiversidad de raíces y tubérculos andinos: Una década de investigación para el desarrollo (1993-2003). No. 6. Lima, Perú: Universidad Nacional de Cajamarca, Centro Internacional de la Papa, Agencia Zuiza para el desarrollo y la cooperación.

11. TALLEDO, D., ESCOBAR, E., \& ALLEMAN, V. 1995. El ciclo celular en vegetales; su estudio, importancia y aplicaciones. Biotempo, 2, 13-31.

12. FERRER, H., ALCORCÉS DE GUERRA, N. C., \& MÉNDEZ, J. R. 2007. Determinación del ciclo mitótico de dos cultivares de Gossypium hirsutum L. y dos ecotipos de Gossypium barbadense L. Acta Biol. Par., Curitiba, 36, 121-149.

13. SCHMIDT-LEBUHN A, FUCHS, J., HERTE, D., HIRSCH, H., TOIVONEN, J., \& KESSLER, M. 2010. An Andean radiation: Polyploidy in the tree genus Polylepis (Rosaceae, Sanguisorbeae). Plant Biology. Publicado online Feb 2010. 
14. RAMSEY, J., \& SCHEMSKE, D. 1998. Pathways, mechanisms, and rates of polyploidy formation in flowering plants. Annual Review of Ecology and Systematic, 29, 467-501.

15. JARA-SEGUEL， P., ROMEROMIERES, M., \& PALMA-ROJAS, C. (2006). Chromosome numbers of Chilean pteridophytes: First contribution. Guyana Botany, 63, 115-118.

16. FERNÁNDEZ, A., KRAPOVICKAS, G., \& SEIJO, A. (2003). Los cromosomas de Malváceas. (Resumen, Universidad Nacional del Norte, 2003). Resumen: B-044.

17. GALINDO, E. 2006. Problemas y ejercicios de probabilidad y estadística. Quito - Ecuador: Policiencia Editores.

18. SINGH, J. 2002. Plant cytogenetic. Illinois, Estados Unidos: CRC Press.

19. SHARMA, A., \& SHARMA, A. 1999. Plants Chromosome, analysis, manipulation end engineering. London. England: CRC Press.

20. MARTINEZ-GOMEZ，P., SANCHEZ-PEREZ, R., VAKNON, Y., DICENTA, F. AND GRADZIEL, T., 2005. Improved technique for counting chromosomes in almond. Scientie Horticulturae 105:139-143

21. SWANSON, C., MERZ, T., \& YOUNG, W. 1981. Cytogenetics. The chromosome in division, inheritance, and evolution. New Jersey, U.S.A: Prentice Hall, INC. Engleaood Cliffs.
22. MATOS, A., \& MOLINA, J. 1997. Estudio citogenético en células radicales de Aloe vera L. Rev. Fac. Agron. (LUZ), 14, 173-182.

23. RAVEN P., EVERT, R., \& CURTIS, H. 1976. Biology of plants. New York, U.S.A.: Worth Publishers, INC.

24. RODRÍGUEZ, V., \& SEIJO, G. 2001. Estudio del ciclo celular de una especie leñosa: Gleditsia amorphoides (Leguminosae). Ciencias Agrarias, 14, 321-324.

25. GOULD, A. 1984. Staning and Nuclear Cytology of Cultured Cells. Indra Vasil (Ed.). In Cell Culture and Somatic Cell Genetics of Plants. Academic Press, Inc., 1, 699-711.

26. IDEHEN, E., KEHINDE, O., \& ADEGBITE, A. 2006. Somatic chromosome counts and yields performance of some accessions of 'egusi' melon (Citrullus lanatus). African Journal of Biotechnology 5, 2049-2052.

27. SCHIMOTSUMA, M 1961. Chromosome number of Citrullus species. Chromosome information service 2, Kyushu, kukuoka. Japan.

28. KESSLER, M. 1995. The genus Polylepis (Rosaceae) in Bolivia. Candollea, 50, 31-71.

29. SIMPSON, B. B. 1979. A revision of the genus Polylepis (Rosaceae: Sanguisorbeae). Smithsonian Contributions to botany, 43, 1-62. 